study of the human use of the oceans. They estimated that a third of the oceans' production goes to support human fisheries another stunning number in view of the fact that, not too long ago, the ocean fisheries were considered to be inexhaustible. Large numbers of fisheries are now depleted or endangered. We are clearly at the limits of ocean exploitation. Further, as Pauly and others have shown, we are now "fishing down the food chain", as the large predatory fish have been depleted.

Pimm concludes his book with a sobering analysis of species losses, his speciality. He ends his analysis with a plea for the preservation of those areas of the world that are particularly rich in species, the so-called 'hot spots'. He claims that we do have the means at hand to "defy nature's end" by purchasing and protecting examples of these areas.

In recent years the international scientific community has made an enormous effort to carefully document, through the International Panel on Climate Change, the impact of humans on the Earth's climatic system. The panel has concluded that human action is indeed altering the climate of the Earth with profound consequences for the way we will live our lives. Pimm does not deal with the consequences of these changes, nor with the escalating disruptions due to the biological homogenization of the Earth's biota. He purposely omitted considering future changes and concentrated on what we know now and for certain. Putting where we are today together with what the future most probably holds for the biotic systems on which we depend certainly gives cause for concern. Let's hope that Pimm's book will educate more of us on what the stakes are and why we need to move urgently towards a more sustainable use of our resources than we are seeing today.

Harold Mooney is in the Department of

Biological Sciences, Stanford University,

Stanford, California 94305, USA.

\section{Discourse and discord}

Reconciling Science and Religion: The Debate in Early Twentieth Century Britain

Peter J. Bowler

University of Chicago Press: 2001. 496 pp.

$\$ 40, £ 24$

Rebuilding the Matrix: Science and Faith in the 21st Century Denis Alexander

Lion Publishing: 2001. 544 pp. $£ 20$

\section{Geoffrey Cantor}

These timely books form part of the rapidly expanding body of literature on the interrelations between science and religion.
Bowler, an historian of science who disavows any religious convictions, has addressed a significant lacuna in existing scholarship. Whereas much has been written on the Victorian controversies, often focusing on the scientific naturalism and materialism spearheaded by Thomas Henry Huxley and John Tyndall, little attention has been paid to the opening decades of the twentieth century. The Scopes trial of 1925, which considered whether the state of Tennessee could prosecute John Scopes for teaching the theory of evolution in a public-school science class, is the best-known event of this period. But it had little impact on British writers, who inherited a very different set of religious and social assumptions compared with their American counterparts.

Bowler's main contention is that, during the early twentieth century, discussion of science-religion issues in Britain was dominated by reactions against Victorian naturalism. With agnosticism and materialism considered as passé, many scientists, theologians and popular writers sought a new rapprochement between science and religion. Although a few atheists, such as E. Ray Lankester and Arthur Keith, continued the assault on Christianity, they were considerably outnumbered by those who advocated some form of synthesis.

Yet there was no consensus on how this synthesis should be achieved. Responses ranged from Oliver Lodge's advocacy of spiritualism, which linked the worlds of matter and spirit, to Arthur Eddington's enthusiastic embrace of the new physics in 1927 which, he claimed, only then made religion "possible for a reasonable scientific man". Whereas Bishop Ernest Barnes advocated an effervescent mixing of science with progressivist, evangelical Christianity, churchmen of a more conservative stripe, such as Charles Gore, sought a reconciliation that preserved traditional Christian doctrines.

One of the great strengths of Bowler's book is that it demonstrates the richness of science-religion discourse during this period and provides a helpful map of the terrain. Not only does Bowler discuss the more eminent scientists and theologians, whose positions have previously been analysed, but he sheds considerable light on several lesserknown figures. He also shows that issues of science and religion were subject to comment and controversy far beyond both professional communities. The public, for example, encountered these issues in newspapers, in the periodical press and in books aimed at a wide readership. Thus, authors as diverse as H. G. Wells, G. K. Chesterton and Bertrand Russell are included in Bowler's analysis. Given the considerable range of commentators discussed, it is not surprising that Bowler has paid less attention than he might to the broader social and political movements of the period that impinged on

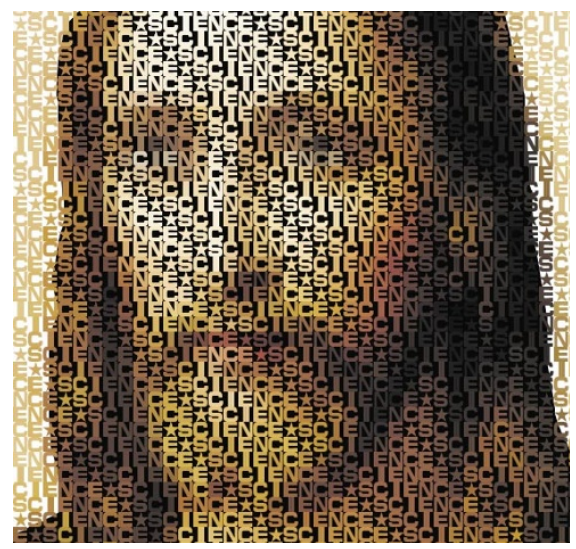

the religious and scientific life of Britain.

The lively interest in issues of science and religion during the opening third of the century and the attempt to transcend the Victorian impasse had given way to a less favourable atmosphere by the late 1930s. Increasing politicization and the rise of a new generation of scientists with different agendas led to a greater polarization of positions and a lowering of interest in the topic. Although the discussion of science and religion received a further boost in the postwar period, largely through Charles Coulson's writings, it has regained prominence only during the past few years. The other book under review reflects this trend.

As a molecular immunologist and committed Christian, Denis Alexander is troubled by two popular prejudices of our age. One is the opposition to science (which has sometimes been promulgated in the name of religion); the other is the assumption that science and religion are locked in necessary conflict (a belief that is often advanced in the name of science). To counteract both prejudices, Alexander has written an introductory and wide-ranging text that is intended to encourage the reader to adopt a more tolerant position, particularly on the issue of science and religion, on which atheists such as Richard Dawkins and Peter Atkins have grabbed the public's attention.

To engage this topic, Alexander has to clear the undergrowth by introducing an extensive range of issues that concern both scientific knowledge and religious knowledge (as opposed to belief). Although he acknowledges the role of social factors, he adopts a critical realist stance towards science, rejecting not only the dogmatic image of science that is often conveyed to the public, but also the threat of relativism. On this and other epistemological issues, he conceives close parallels between science and Christianity. Although some of these correspondences are more convincing than others, they not only refute the much-vaunted conflict thesis but also indicate how science and religion can be located in the same epistemological frame.

Alexander also insists that the theory of 
evolution has neither religious nor metaphysical implications, and should therefore not be extrapolated into such areas as evolutionary ethics. Although many practising scientists will support his position, it cannot be implemented because, as Bowler's study shows, reflection on the wider connotations of scientific theories has proved both important and attractive to many writers, including some scientists. Alexander's strategy of guarding science against questionable implications nevertheless enables him to combat both the anti-religious scientism of atheists such as Dawkins and the anti-evolutionism of creationists. Proponents of both positions, he claims, have misunderstood both science and religion. Indeed, proponents of these twin heresies have misinterpreted the opening verses of Genesis, which should not be read as a proto-scientific account describing how the world came into existence, but should be understood in the context of the creation stories that were current at the time it was written.

Alexander also provides a long and informative overview of the history of sciencereligion interactions from the ancients to the Victorian controversies surrounding darwinism and materialism. From this survey he draws the possibly over-optimistic conclusion that, in the past, science and religion have interacted in many different ways and to the benefit of both parties. Interestingly, his historical survey stops short of the period that is illuminated by Bowler's book. Although some of Alexander's arguments reflect those used in the period discussed by Bowler, Alexander's contribution to science and religion helps to move the subject into the twenty-first century. Geoffrey Cantor is at the School of Philosophy, University of Leeds, Leeds LS2 9JT, UK.

\section{Washing one's hands of controversy}

\section{Prometheans in the Lab: \\ Chemistry and the Making of the Modern World \\ by Sharon Bertsch McGrayne \\ McGraw-Hill: 2001. 243 pp. \$24.95 \\ Martyn Poliakoff}

When Prometheus stole fire from the gods, he had to endure their wrath. But he did not have to worry about the effect of fire on the environment when he released it on Earth. That was the users' problem. Things were different for the revolutionaries of industrial chemistry, the 'Prometheans' of the title. The gods did not interfere but the environmental consequences came back to haunt them.

However, the Prometheans fought back. When Thomas Midgely, the inventor oflead- ed petrol, was asked at a press conference whether his new additive was dangerous when spilled on the hands, he "called for tetraethyl lead. Pouring it into his palms, he washed his hands with it, and then held the bottle to his nostrils for more than a minute. Drying his hands on his handkerchief, he announced, 'I'm not taking any chance whatever." Midgely knew it was untrue but it was the message the public wanted to hear. Lead cured the knocking that crippled car engines and reduced petrol consumption. Lead was needed to drive the United States through the twentieth century.

The balance between consumer benefit and environmental impact is not clear-cut, and this is the crux of Sharon Bertsch McGrayne's ambitious book. Her case is built around the lives of outstanding chemical inventors from the eighteenth century to the present day. Their lives illustrate the interplay of consumer demand, corporate greed and environmental fallout.

The inventors are not all well known but they have been chosen with care, albeit with a slight bias towards the United States. They include: Nicolas LeBlanc, the inventor of an extremely smelly and polluting method for producing washing soda, who lost his patents during the French Revolution; William Perkin, the 18-year-old English inventor of the first synthetic purple dye, who retired a millionaire at the age of 35 to devote himself to scientific research; Norbert Rillieux, an African-American chemical engineer and cousin of the painter Degas, who introduced a revolutionary steam evaporator for refining sugar; Edward Frankland, the British founder of analytical chemistry and champion of clean water, who suffered from the lifelong stigma of his illegitimacy; Fritz Haber, the German inventor of the eponymous process for making ammonia from atmospheric nitrogen and chief proponent of chemical warfare in the First World War, whose first wife committed suicide in disgust at his war role (or was it at his infidelity?); Thomas Midgley, the 'lead handwasher', who also invented ozone-depleting CFC refrigerants and arranged to be strangled by the contraption that he devised to turn him in bed after he was struck down by polio; Wallace Carothers, inventor of nylon and founder of polymer science, who was an alumnus of the same little-known college as Carl Djerassi, inventor of the contraceptive pill; Paul Müller, the Swiss inventor of the insecticide DDT, whose boss contested his Nobel prize; and the US geochemist Clair Patterson, who established the age of the Earth and then went on to show that it was polluted even at its utmost ends bylead from gasoline.

Bertsch McGrayne is a science journalist and really comes into her own when the book moves into the twentieth century. She has missed some well-known anecdotes that could have enlivened the earlier chapters, such as Perkin's luxuriant beard from which debris was reputed to fall into his solutions to nucleate crystallization. But many fascinating stories are there, including Haber's vain and highly secretive attempt to fund Germany's war reparations by extracting gold from sea water.

One of her main arguments, which I strongly support, is that we should not apply environmental judgements to historical situations without considering their humanitarian context. Thus, the first large-scale application of DDT was made during a typhus epidemic in Naples in December 1943. Within three weeks, the civilian death toll had halved, the first time that a typhus outbreak had been controlled in winter. Similarly, one of the main benefits of CFCs was safe refrigeration, which not only reduced food poisoning but also allowed the widespread use of vaccines, for example in eradicating smallpox. That said, the book contains several examples in which the needs of corporate profit and human welfare clearly diverge.

Bertsch McGrayne explains how, as a Jew, Haber was airbrushed out of history by the Nazis. However, his former colleagues circumvented the Nazi boycott of his memorial service by sending their wives in their place. But she fails to point out the interesting moral contradiction in Haber's work. His ammonia process was invented to make fertilizers to relieve hunger, yet it was used for explosives that killed millions. He invented mustard gas as a weapon, but its derivatives have saved the lives of more cancer patients than it ever killed soldiers on the battlefield.

This is not a chemistry book; the chemistry it does contain is painfully spelled out. It is well researched, but the author eschews footnotes and her sources are hidden in a somewhat idiosyncratic "annotated bibliography”. There are a few line diagrams but no pictures, which is a pity in a book that is so centred on personalities. From the prelude to the quaintly named "postlude", it is a compelling read, provided that you persist beyond the opening chapters.

Martyn Poliakoff is at the School of Chemistry, University of Nottingham, University Park, Nottingham NG7 2RD, UK.

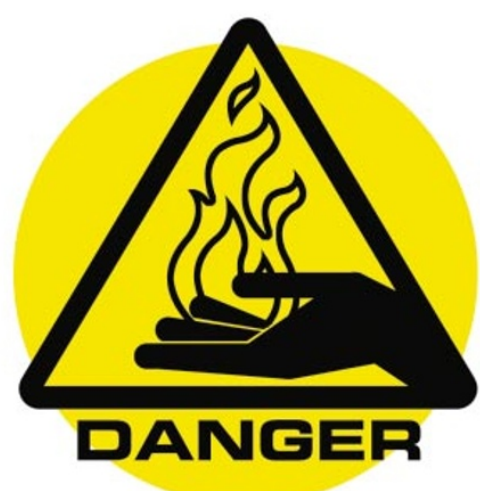

